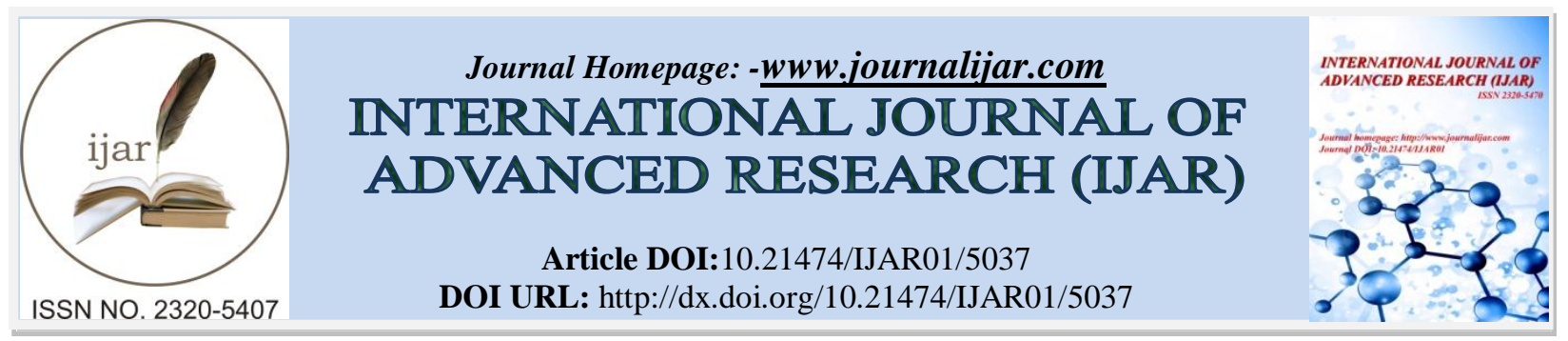

RESEARCH ARTICLE

\title{
IMMUNOHISTOCHEMICAL ESTIMATION OF FOXP3 EXPRESSION IN T-REG AND CANCER CELLS IN IRAQI LUNG CANCER TISSUE.
}

\author{
Suhad Faisal HatemAl-Mugdadi ${ }^{1}$, Waleed M.Hussen ${ }^{2}$ and Mustafa N. A. Ali ${ }^{3}$. \\ 1. Department of clinical laboratory sciences, Pharmacy college Al-Mustansiriyah University, Baghdad, Iraq. \\ 2. Consultant Thoracic and vascular surgeon, Bagdad University, Baghdad, Iraq. \\ 3. Consultant chest physician, Bagdad University, Baghdad, Iraq.
}

\section{Manuscript Info}

Manuscript History

Received: 01 June 2017

Final Accepted: 03 July 2017

Published: August 2017

Key words:-

FOXP3, T-reg, lung cancer, IHC.

\begin{abstract}
Lung cancer is the most common cancer worldwide accounting for 1.61 million new cases annually and it is the most common reason of death from cancer in different regions. FOXP3 is immune marker known to be expression in T-regulatory cells. Recently, it has been confirmed that the tumor cells themselves can express FOXP3 leading to the tumor development and metastasis. Studies combining FOXP3 and lung cancer worldwide are very few. None of them was conducted in Iraq, therefore we aimed to this study. Formalin fixed paraffin embedded tissue blocks were selected for Immunohistochemistry study. streptavidin-biotinimmunoenzymatic antigen detection system was used. The number and intensity of FOXP3+ cells present within tumorcell nuclei ,cytoplasm and T-reg infiltrating cells were counted and scored.

Twenty two cases (73.3\%) of lung cancer showed positive IHC expression of FOXP3 in the lymphocytic infiltrate, 21(70\%) cases of lung cancer revealed positive nuclear expression in the tumor cells compared to only $3(13.63 \%)$ cases of benign lesions and $23(76.7 \%)$ cases of lung cancer revealed positive cytoplasm expression .There is a high significant difference was noted between malignant and benign groups regarding the nuclear expression of FOXP3 p<0.001, as well as between cytoplasm expression. The highest score to be detected in nuclear expression of FOXP3 was score 3 in11 (36.67\%) with high intensity $16(53.3 \%)$ in malignant cases. While highest frequency of cases was noticed in score 1 of FOXP3 positive infiltrating lymphocytes $14(46.67 \%)$ in malignant cases with high intensity $18(60 \%)$. The present study results suggest that FOXP3 is useful immune markers with potential applications as prognostic markers in lung cancer.
\end{abstract}

Copy Right, IJAR, 2017,. All rights reserved.

\section{Introduction:-}

Lung cancer is the most common cancer worldwide, the new cases accounting 1.61 million annually , $12.7 \%$ of all new cancers and it is the most common reason of death from cancer, with 1.38 million deaths (18.2\% of the total). The common of the cases now occur in the developing countries with percentage 55\% [1]. Lung cancer rates are 
particularly high in central-Eastern and Southern Europe, Northern America and Eastern Asia. it is considered now the fourth most frequent cancer of women $(513,000$ cases, $8.5 \%$ of all cancers) and the second most common cause of death from cancer $(427,000$ deaths, $12.8 \%$ of the total) [2]. In Iraq , lung cancer consider the second cancer after breast with incidence rate about $4.96 / 100,000$ population, and first cancer causing deaths (13.82\%) within Iraqi people[ 3].

Approximately $85 \%$ of lung malignant tumors are NSCLC (squamous cell carcinoma(SCC), adenocarcinoma and large cell carcinoma) and about $15 \%$ of them are SCLC [4]. Several investigators have studied an opposing aspect of the immune system, and the function of T regulatory (Treg) cells [5,6]. T-reg cells may down-regulate the immune response by attenuating the host's antitumor $T$ cells, potentially permitting growth and metastasis [7]. Studies indicate an over account of Treg in the peripheral blood of patients with solid tumors [8,9]. Furthermore, an increased accumulation of Treg in the tumor mass goes along with an adverse prognosis and metastasis [10,11]. It has been assumed that Tregs were the main cell type mediating immune suppression regulated by expression of forkhead box transcription factor (FOXP3). It has been confirmed that the tumor cell itself can express FOXP3, However, the finding that FOXP3 is expressed in tumor cells implies that T-cell action may be modulated not only by FOXP3 in T-regs but also by tumor-associated FOXP3 [12]. The hypothesis that the expression of FOXP3 in tumor cells is a new mechanism of tumor cells escaping immunity and it may be related with poor prognosis has been proposed $[13,14]$.

All authors are in agreement to consider T-reg lymphocytes as CD4+CD25+ cells, but at present it is still unknown whether the expression of CD4 and CD25 antigens enough to recognize T-reg cells . The intra cytoplasmatic expression of the FOXP3 protein is essential for the differentiation into T-reg cells [15,16] .As far as ,the mechanisms responsible for T-reg induced suppression of the anticancer immunity are concerned, several experimental observations have revealed that T-reg cells may suppress the antitumor immune response throughout the release of immunosuppressive cytokines, namely TGF- $\beta$ and IL-10 [17]. As most tumor antigens are selfantigens [18], T-reg-cell-mediated suppression of TAA-reactive lymphocytes has been proposed as a possible mechanism to clarify the failure of antitumour immunity [19,20]. Both T-reg cells and CD8+ regulatory T cells have been reported in the context of human tumour immunity [16]. Study confirmed that, the metastatic disease is linked with increased T-reg generation and a following suppression of anticancer immunity in many kinds of tumor (Nonsmall cell lung cancer ,Breast cancer, Colorectal cancer,Gastriccancer,Pancreaticcancer,Prostate cancer and Gynaecologic neoplasms [11].

Evidence that FOXP3 is also expressed by tumor cells, given the essential contribution of FOXP3 to Treg function, and that may represent a novel mechanism by which cancers suppress the immune system to escape destruction. These observations hint are interpretation of previous studies in which T-reg prevalence in tumors was investigated by measuring FOXP3 transcripts in the tumor tissue, as some of these transcripts may have originated from the tumor cells themselves and not from T-reg. Clearly, these explanations raise the possibility of inducing tumor immunogenicity by knocking down FOXP3 expression [21].Unequivocal proof that FOXP3 is expressed both at the protein and transcript protein level by tumour cells of various types (lung cancer, colon cancer, breast cancer, melanoma, erythroidleukemia, acute T-cell leukemia) correlated with the expression levels of TGFb1 and IL-10 [22] .Also the expression of FOXP3 in patients with tumor tissues of breast[23], pancreas[13], ovarian [24], melanoma[25], lung([26], colorectal[27] oesophageal [28]and gastric cancer [29] have been reported.

To determine whether the expression of FOXP3in the production of a mature protein, tumorprotein expression were examined by immunohistochemistry and by flow cytometry for intracellular expression of FOXP3, using different antibody clones.It has been used as prognostic marker for human tumors . In addition FOXP3mRNA expression was examined using both conventional PCR or quantitative real-time PCR (qRT-PCR) [9,26,28,30].

\section{The Aim of Study:-}

Studies combining FOXP3 and lung cancer worldwide are also very few. None of them was conducted in Iraq.It was hypothesized that since Iraqi patients with lung cancer usually have poor prognosis, then one must study the expression of important marker in these tumors. Thus Immunohistochemical estimation of FOXP3 in Treg and cancer cells in formaline fixed paraffin embedded (FFPE) of Iraqi NSCLC tissue was achieved. 


\section{Materials and Methods:-}

Samples: This part of project was done in the laboratories of Oncology hospital \& specialized surgery hospital /Medical City /Baghdad.The study coverd the period from June 2012 to June 2014.In the immunohistochemical part of the study, formalin fixed paraffin embedded tissue blocks were selected from 30 cases with different type of lung cancer .twenty two cases with benign lung lesion including chronic bronchitis and emphysema were submitted to IHC staining and served as a control sample. The sample was selected from the laboratory archives of the same hospitals.

\section{Detection of FOXP3 Proteins expression:-}

Paraffin embedded sections of lung cancer and benign lesion were sectioned into $4 \mu \mathrm{m}$ thicknesses using a microtome instrument. The sections were placed on Kling-onHIER positively charged slides and left them overnight in an oven at $65^{\circ} \mathrm{c}$. Polyvalent HRP/DAB Detection kit for mouse and rabbit (IHC)/ Abcam (Canda) also Primary antibody FOXP3 (abcam 22510) were used according to the manufacturer's instructions. kit have a labeld streptavidin-biotinimmunoenzymatic antigen detection system, involving the sample incubation with unconjugated primary antibody specific to target antigen.biotinylated secondary antibody reacts with primary antibody and this complex with chromogen makes the reaction visible at the antigen site to be examined under microscope.

\section{Scoring Analysis:-}

The slides were examined by light microscope 10X, 40X, 100X and after comparing the sections slides with negative and positive control slidesthe score was determined. The number of FOXP3+ cells present within tumorcell nuclei were counted and scored manually in 10 high-power fields (HPFs; magnification, x400). No nuclear staining cells $(0), 1-5$ cell $(+1), 6-19$ cell $(+2), 20$ and amore cell $(+3)$ according to [31], lymphocyte infilterating cells were scored as no staining cells $(0), 1-25 \%$ cells $(+1), 26-50 \%$ cells $(+2), 51-100 \%$ cells $(+3)$ according to $[23,7]$. Cytoplasm FOXP3 expression was scored as no staining Intensity was scored negative staining, low, moderate, and high or strong staining according to deep of brown color of the marker.

\section{Statistical Analysis:-}

Frequencies and percentage were calculated out from the total of malignant samples and from the total benign samples.The Statistical Analysis System-SAS (2010) was applied in this work. The difference was considered significant when the $(\mathrm{P})$ value was $\leq 0.05$.

\section{Results and Discussion:-}

Twenty two (73.3\%) cases of lung cancer showed positive IHC expression of FOXP3 in the lymphocytic infiltrate compared to $15(65.2 \%$ ) cases of benign lesion.On the other hand,21(70\%)cases of lung cancer revealed

Positive nuclear expression in the tumor cells compared to only 3(13.63\%)cases of benign lesions. Twenty three $(76.7 \%)$ cases of lung cancer revealed positive cytoplasmic expression compared to 14(60.9\%)of benign lesion. In tumor cells, a highly significant difference was noted between malignant and benign groups regarding the nuclear expression of FOXP3 p $<0.001$, as well as between cytoplasmic expression of malignant and benign lesion $\mathrm{p}<0.05$. However, there was no significant difference in the infiltrating lymphocytes expression between malignant and benign lesions $\mathrm{p}>0.05$ (Table 1).

Table 1:-Frequency distribution of FOXP3 positive protein expression according to localization in cancer and benign tissues

\begin{tabular}{|l|c|lcc|}
\hline $\begin{array}{c}\text { Kinds of } \\
\text { samples }\end{array}$ & $\begin{array}{c}\text { Total } \\
\text { number }\end{array}$ & $\begin{array}{l}\text { Nuclear** } \\
\text { NO.\% }\end{array}$ & $\frac{\text { Cytoplasm }^{*}}{\text { NO.\% }}$ & $\frac{\text { Lymphocyte }}{\text { NO.\% }}$ \\
\hline Malignant & 30 & $21(70)$ & $23(76.7)$ & $22(73.3)$ \\
Benign & 22 & $3(13.63)$ & $15(65.2)$ & $14(60.9)$ \\
\hline
\end{tabular}

Scoring of the expression of any marker is an important step to relate that expression to different parameters. In the present study, the highest score to be detected in nuclear expression of FOXP3 was score 3in11(36.67\%) malignant cases(Figure 1).The high intensity also predominated 16 cases(53.3\%)in malignant cases as well(Figure 2). 


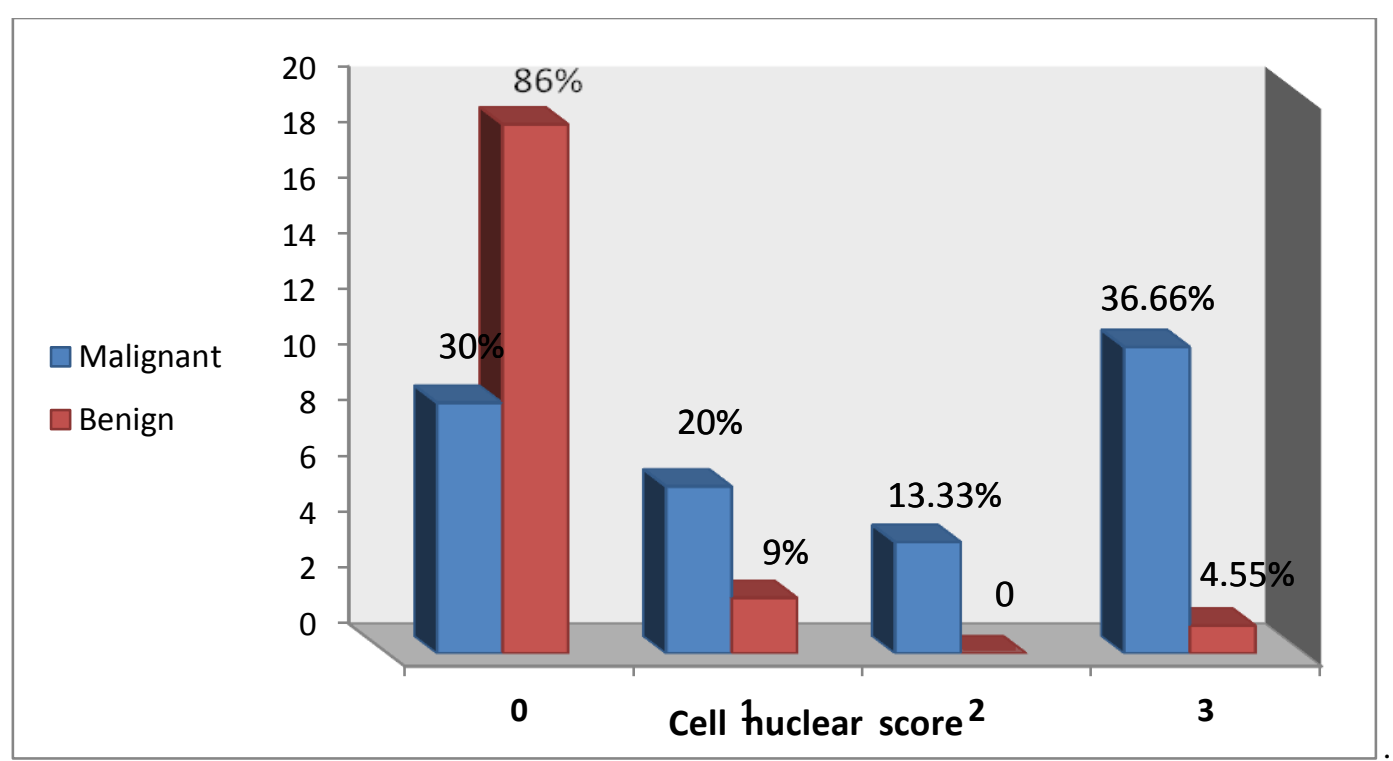

Figure (1):- Frequency distribution of lung cancer cases and benign lesions according to the nuclear expression score of FOXP3 in epithelial cells (malignant and benign).

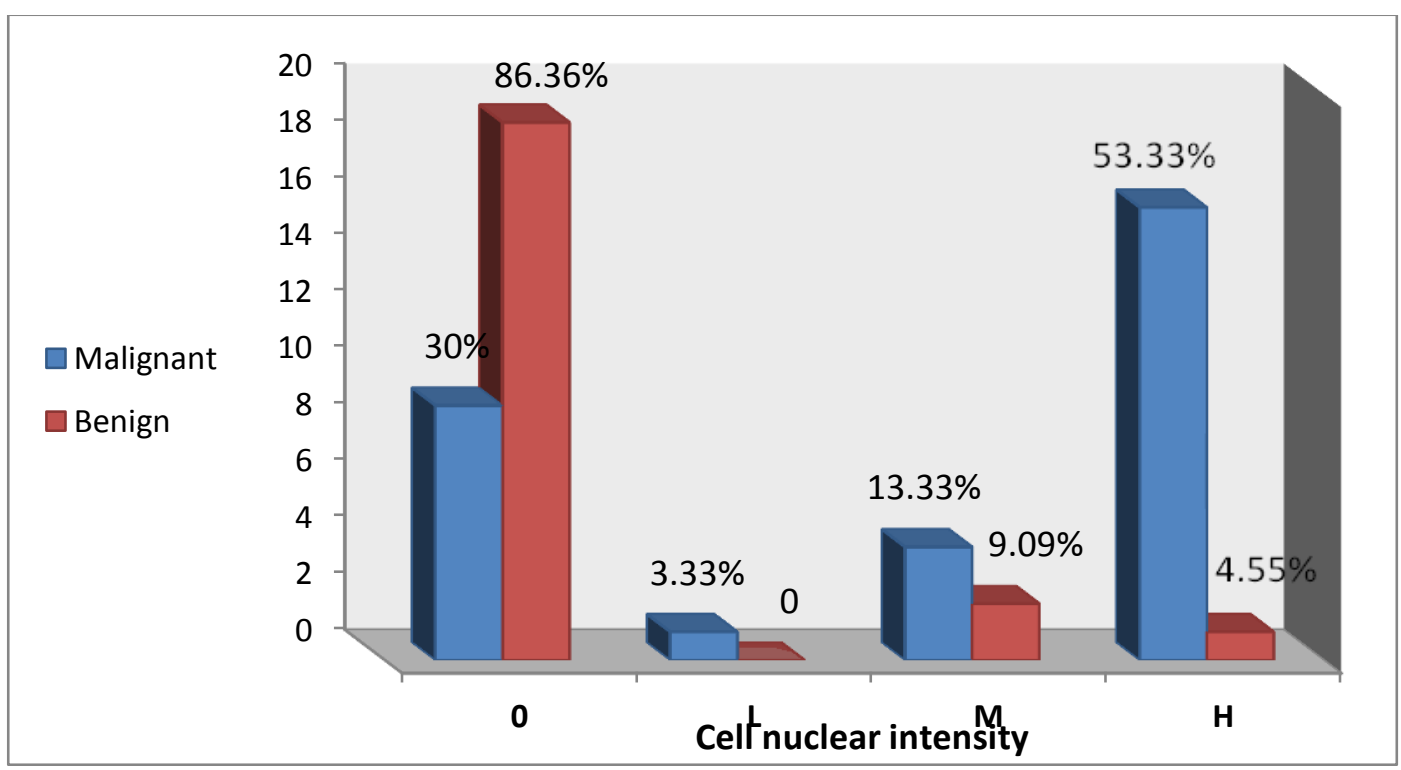

Figure (2):- Frequency distribution of lung cancer cases and benign lesions according to the intensity score of nuclear expression of FOXP3 in epithelial cells (malignant \& benign). L= Low ,M=Moderate ,H=High.

In cytoplasm, low intensity dominated other intensity scores both in malignant and benign lesion 13(43.33\%) and $9(40.91 \%)$ respectively. However, high intensity expression was only detected in malignant cases 5(16.67\%) (Figure 3) . Figure 4(A\&B) different cases of lung cancer tissues stained with anti-FOXP3 antibody in IHC reactions. Different scores and intensities are detected in nuclear and cytoplasm locations. 


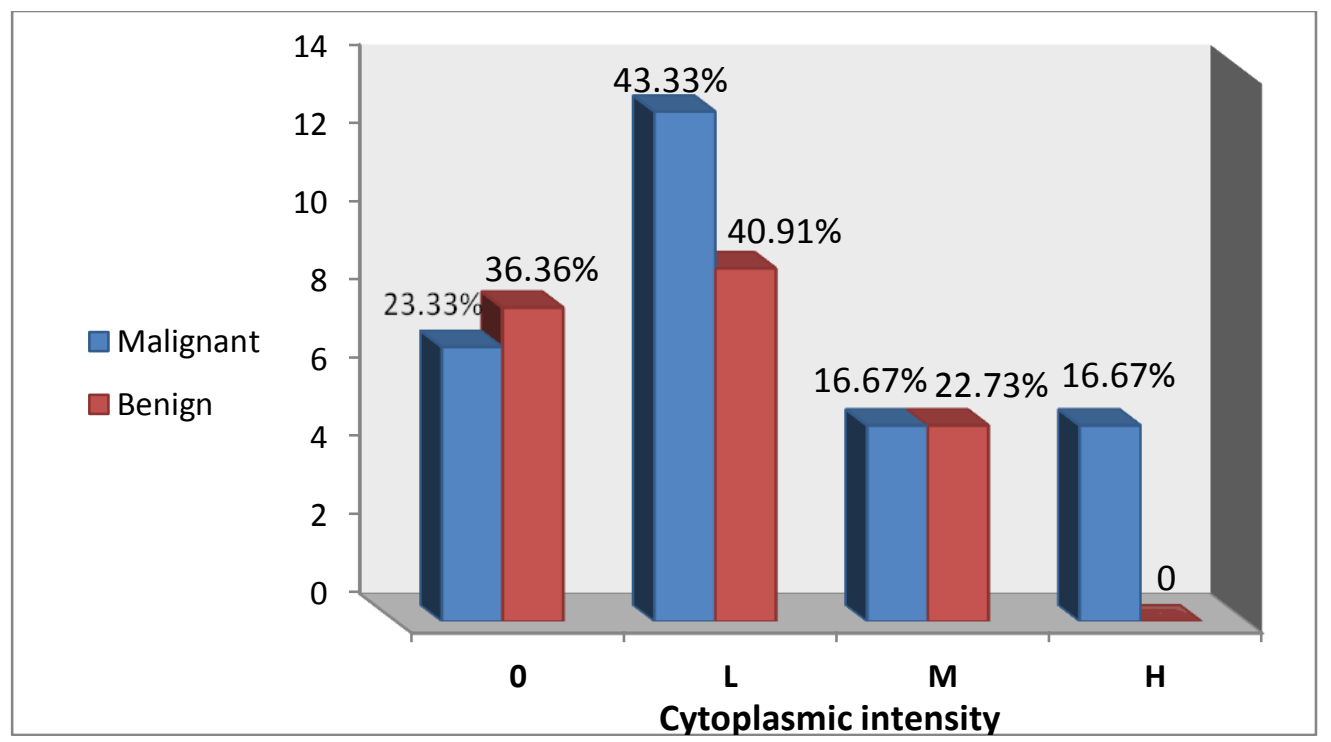

Figure (3):- Frequency distribution of malignant and benign lesions according to the intensity score of FOXP3immunohistochemical expression in a cytoplasmic localization both in malignant and benign epithelial cells.L=Low,M=Moderate,H:High.

A

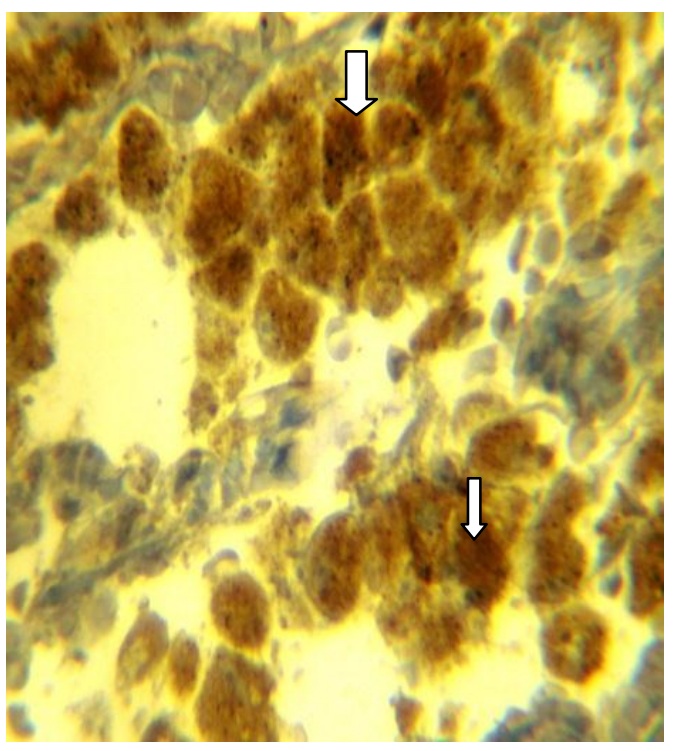

B

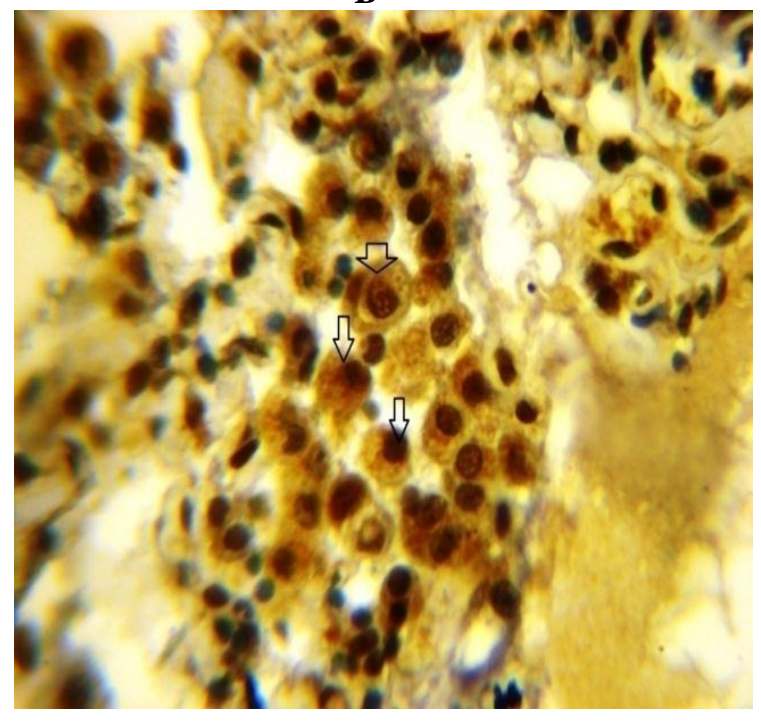

Figure 4:- A cases of Adencarcinoma(A)\&Undifferentiated large cell carcinoma(B) of the lung showing positive nuclear FOXP3 immunostaining(score 3) and high intensity cytoplasm expression (arrows)(40X).

In the present study, due to in availability of flowcytometry at the time of study design, this was substituted by immunohistochemical detection of FOXP3 expression in tissue sections. However, lymph node examination was not feasible since most of the sections were performed on biopsy specimens. Tumors were inoperable or resections did not involve lymph node clearance. It is well known that lymphocytic infiltration of any tumor is an indication of good immune response [32].In their work, [13] suggested that Treg infiltrating any tumor triggers immune evasion of tumor cells through FOXP3 expression. The present data also revealed a significant association between nuclear and cytoplasmic FOXP3expression in both cases of lung cancer and benign lesions (Table 1).This is an indication that FOXP3protein produced in the cytoplasm is inactive unless being expressed in the final functional site, the nucleus. $[30,33]$ had both confirmed the expression of FOXP3 in the nuclei and cytoplasm of lung cancer. The association between cancer cell expression (nuclear or cytoplasmic) and lymphocytic expression was not signifigant 
$\mathrm{p}>0.05$, Table (1) suggesting a different function of FOXP3 expression in both types of cells. [23] have also given explanation to such finding,but in breast cancer.[34]have also noticed an over expression of FOXP3 in cases of NSCLC cases in comparison with non neoplastic lung tissue. Cytoplasmic expression of FOXP3 was examined in the present work to study the ability of an epithelial cell (benign or malignant) to synthesize this protein. Since marker expression in the cytoplasm of any cell does not reflect positively of that cell to it [34].By this, it is regarded as non-specific reaction offcorse unless the protein(marker) has a functional cytoplasmic localization [23]. On the other hand, synthesize of the protein in any particular cell is a reflection of gene expression in that cell[22].

According to the FOXP3expression in tumor microenvironment, the highest frequency of cases was noticed in score 1 of FOXP3positive infiltrating lymphocytes 14(46.67\%)in malignant cases and14(63.64\%) in benign lesions(Figure 5).However a high frequency was noticed in the high intensity groups both of the malignant and benign lesion 18(60\%) and 10(45.45\%)respectively as shown in Figure (6).Figure(7)shows FOXP3positive T-reg in tumor microenvironment in a case of lung cancer.

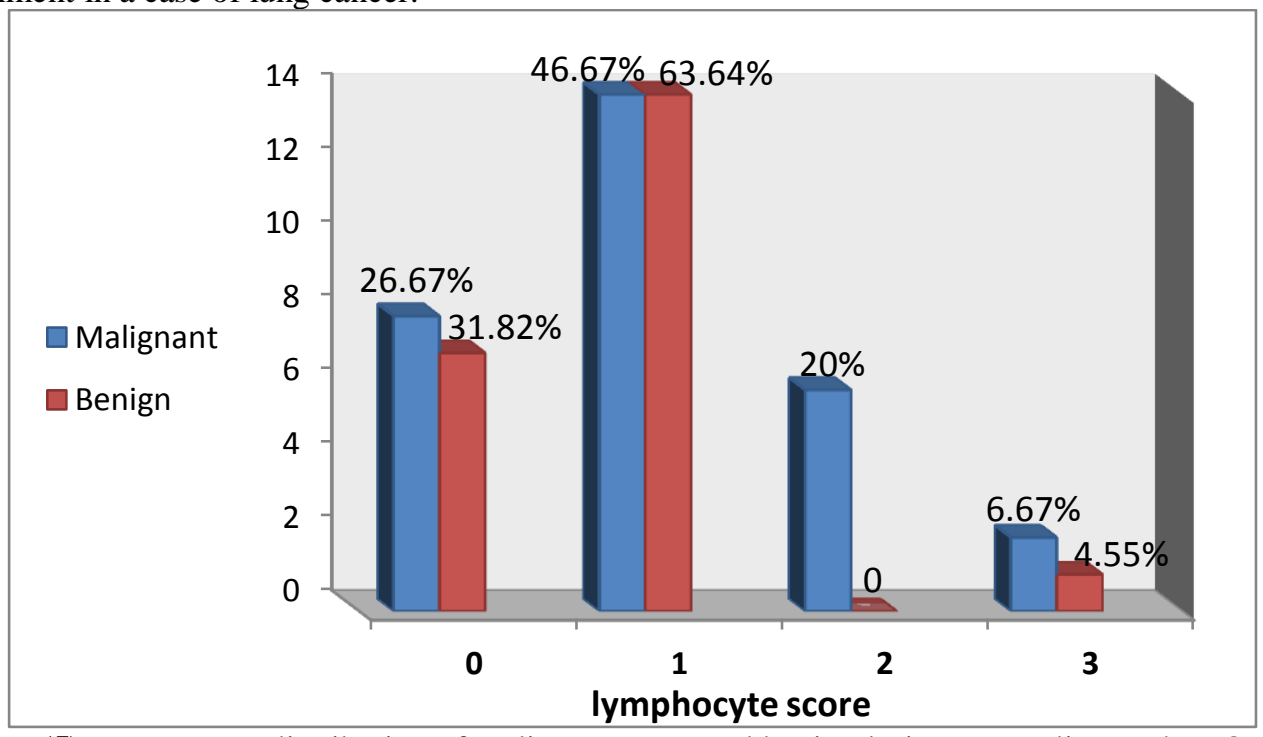

Figure (5):- Frequency distribution of malignant cases and benign lesions according to the FOXP3 IHC expression percentage score of in filtrating Treg in lesion microenvironment.

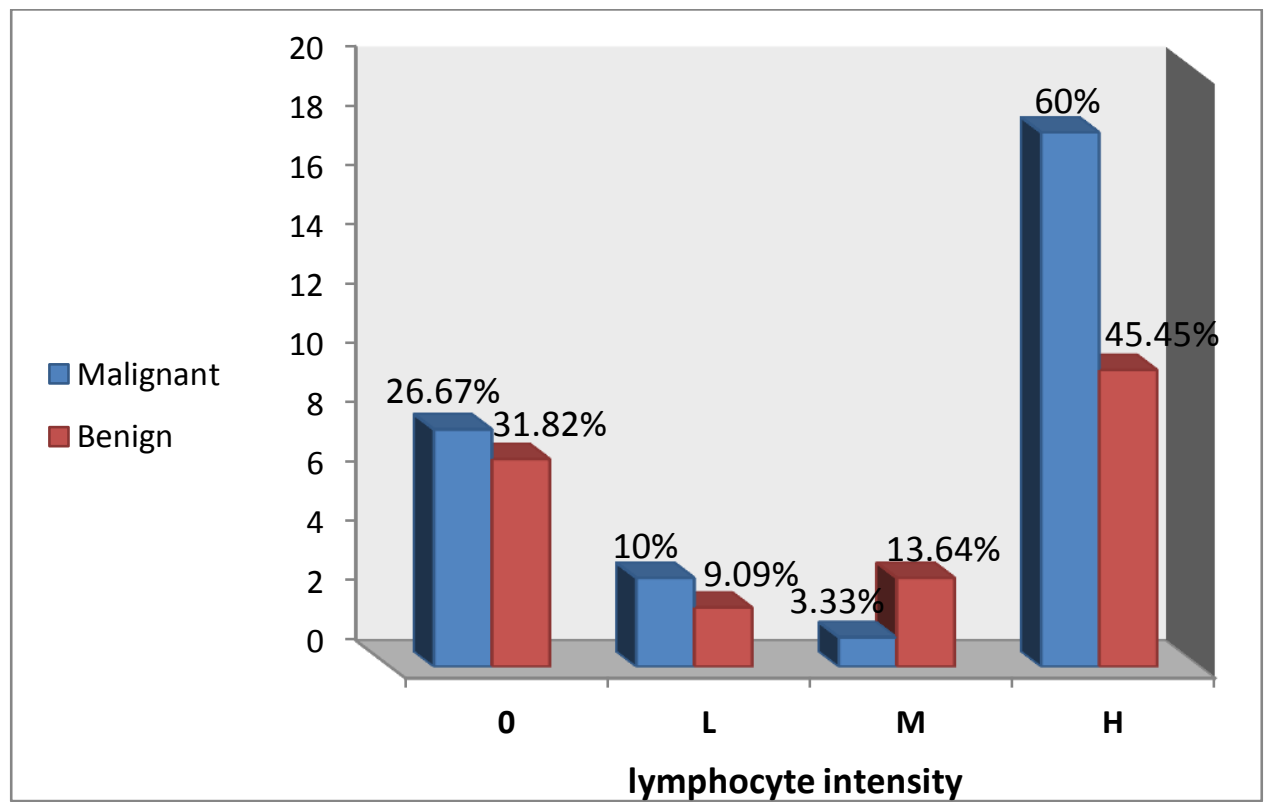

Figure (6):-Frequency distribution of lung cancer cases and benign lesions according to FOXP3 IHC expression intensity score in Tregsinfilterating the lesional microenvironment. $\mathrm{L}=\mathrm{Low}, \mathrm{M}=$ Moderate, $\mathrm{H}=\mathrm{High}$. 


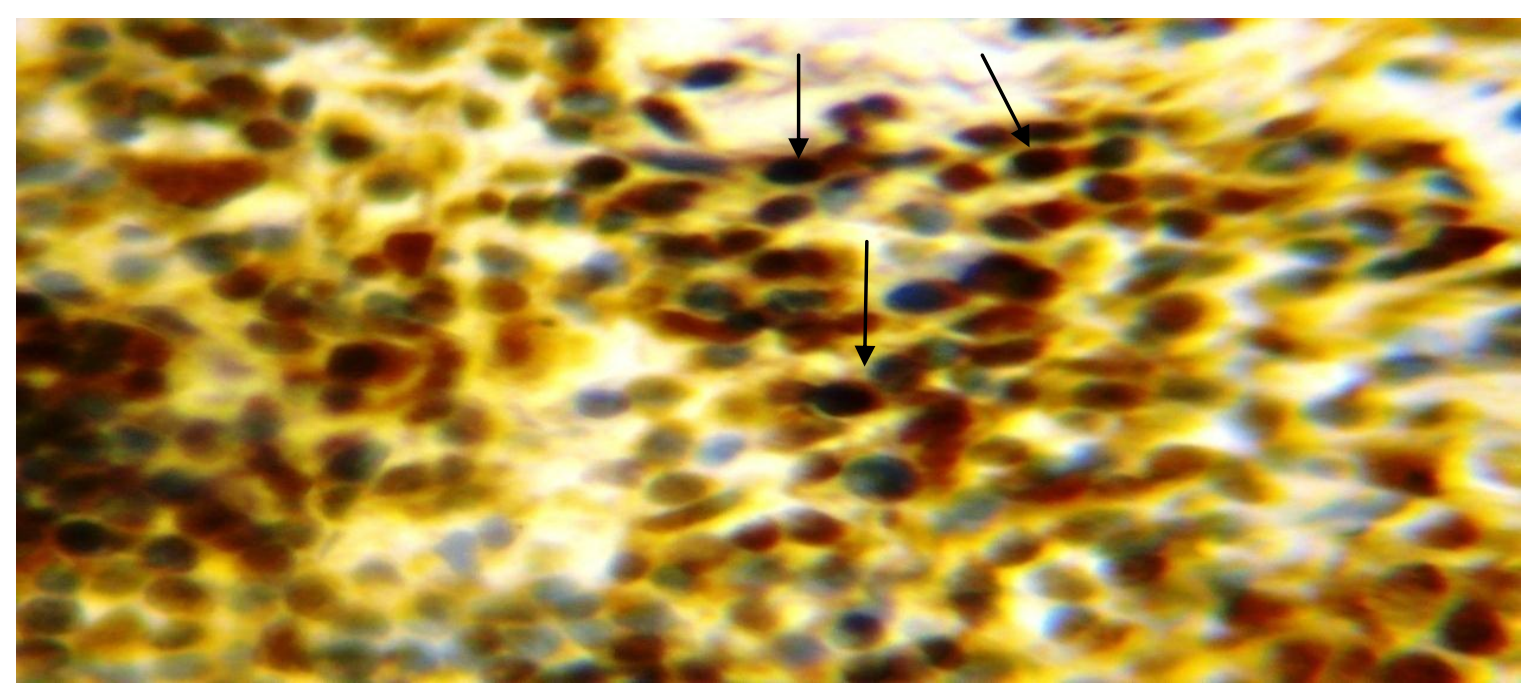

Figure (7):-Acase of adenocarcinoma, showing positive FOXP3 IHC expression in Treg infiltrating tumor microenvironment (arrows)(40X).

Many reaserchers suggested that increase number of FOXP3lymphocytes in tumor microenvirnment may stimulate negative regulation of immune response to tumor cells and promote invasion and metastasis. [35] suggested that a high frequency of FOXP3lmphocytes infiltrating tumor is associated with favorable prognosis in colorectal carcinoma. FOXP3expression mediated by cancer cells rather than by Treg cells contribute to disease progression [27]. In breast cancer, FOXP3 was found to be down regulated compared to normal tissue [36].FOXP3expression in melanoma or pancreatic tumor cells may have Treg like activity thus suppressing effector T cell activity[21].From these observations, it seems likely that FOXP3 expression does not influence carcinogenesis and cancer development in uniform manner but it has a rather cancer type-depended function [34]. In NSCLC, [37] found no significant relationship between Treg count and tumor FOXP3status.In their study,patients without tumor FOXP3 expression and high Treg count had significant worse overall and relapse-free survival than other groups. Study suggested that the different expression of FOXP3 in tumor cells and infiltrating lymphocytes is affected by factors present in the tumor microenvironment such as PGE2, COX-2 and TGF- $\beta[9]$. The immunohistochemical expression of FOXP3 in NSCLC tissue was consistant with qRT-PCR results for FOXP3 mRNA and both significantly differed from the peritumoral lung tissue [33]. It is suggested that tumor cells acquire the ability to survive and metastasize as a result of a tolerance in antitumor immunity induced by Treg in the tumor stroma during tumor progression [38].In the present study, tumor staging was not possible. Tissue blocks were collected from the laboratory archives whereby most of the clinical follow up data were not present, so that it was difficult to predict the relation of FOXP3 expression in tumor cells or microenvironment to tumor progression.

\section{Conclusion:-}

There was a significant increase in FOXP3immunoexpression in NSCLC cells when compared to that of bronchial cells in benign lesions. The present study results suggest that FOXP3 is useful immune markers with potential applications as prognostic markers in lung cancer.

\section{References:-}

1. Elsayed, I. S.; Jazieh, A-R. and Moore,M.A.(2011). Lung Cancer Incidence in the Arab League Countries: Risk Factors and Control. Asian Pacific J. Cancer Prev. 12: 17-34.

2. Ferlay, J.; Shin, H.R.; Bray, F.; Forman , D.; Mathers , C. and Parkin , D. M.(2010) . GLOBOCAN 2008 , Cancer Incidence and Mortality Worldwide: IARC Cancer Base. Lyon, France: International Agency for Research on Cancer.

3. Iraqi Cancer Registry Center Publications (2009). Ministry of Health, Iraqi Cancer Board/ Baghdad.

4. Travis, W.D.; Brambilla, E. and Riely, G.J.(2013). New Pathologic Classification of Lung Cancer: Relevance for Clinical Practice and Clinical Trials. J. Clin. Oncol. 31 (8):992-10.

5. Woo, E.Y.; Chu, C.S.; Goletz, T.J.; et al.(2001). Regulatory CD4 CD25 T cells in tumors from patients with early-stage non-small. cell lung cancer and late-stage ovarian cancer. Cancer Res. 61:4766-72. 
6. Woo, E.Y.; Yeh, H., Chu, C.S.and et al.(2002). Cutting edge: regulatory Tcells from lung cancer patients directly inhibit autologous T cell proliferation. J. Immunol. 168:4272-4276.

7. Petersen, R. P.; Campa, M. J.; perlazza, J. S.; Onlon, D.; Joshi, M-B.; David H. HarpoleJr, D. H. and PatzJr, E. F.(2006). Tumor Infiltrating FOXP31 Regulatory T-cells Are Associated With Recurrence in Pathologic Stage I NSCLC Patients. CANCER, 107 (12):2866-72.

8. Wieczorek, G.; Asemissen, A.; Mode, F.; Turbachova, I.; Floess, S. Liebenberg, V.; Baron, U.; Stauch, D.; Kotsch, K.; Pratschke, J.; Hamann, A.; Loddenkemper, C.; Stein, H.; Volk, H.D.; Hoffmüller, U.; Grützkau, A.; Mustea, A.; Huehn, J.; Scheibenbogen, C. and Olek, S. (2009).Quantitative DNA methylation analysis of FOXP3 as a new method for counting regulatory $\mathrm{T}$ cells in peripheral blood and solid tissue. Cancer Res., 69(2):599-608.

9. Baratelli, F.; Lee, J. M.; Hazra, S.; Lin, Y.; Walser, T. C. and et al. (2010). PGE2 contributes to TGF- $\beta$ induced T regulatory cell function in human non-small cell lung cancer. Am. J. Transl. Res. 2(4):356-367.

10. Hiraoka, N.; Onozato, K.; Kosuge, T.andHirohashi, S.(2006). Prevalence of FOXP3+ regulatory T cells increases during the progression of pancreatic ductal adenocarcinoma and its premalignant lesions. Clin. Cancer Res. 12:5423-34.

11. Vigorè, L.; Rovelli, F., Massimo Colciago, M.; Giovanna D“eAmico, G.; Di Fede, G. and Lissoni, P.(2008). A clinical study of T-regulatory lymphocyte function in cancer patients in relation to tumor histotype disease extention, lymphocyte subtypes and cortisol secretion Research Article. Cancer Therapy, (6): 699-706.

12. Lu, H.(2009). FOXP3 Expression and Prognosis: Role of Both the Tumor and T Cells. J. Clin. Oncol. 27 (11):1735-1736.

13. Hinz, S.; Pagerols-Raluy, L.; Oberg,H-H.; Ammerpohl, O.; Gru“ssel, S.; Sipos, B.; Gru"tzmann, R.; Christian Pilarsky,C.; HendrikUngefroren, H.; Saeger,H-D.; Klo"ppel, G.; Kabelitz, D.; and KalthoffF,H. (2007).Foxp3 Expression in Pancreatic Carcinoma Cells as a Novel Mechanism of Immune Evasion in Cancer. Cancer Res. 67 (17): 8344-50.

14. Merlo, A.; Casalini „P.; Carcangiu, M.L.; Malventano, C.; Triulzi, T.; Mènard, S.; et al.(2009).FOXP3 expression and overall survival in breast cancer. J. Clin. Oncol. 27:1746-52.

15. Ziegler, S.F. (2006). FOXP3 of mice and men. Annu. Rev. Immunol. 24:209-26.

16. Zou, W. (2006). Regulatory T cells, tumour immunity and immune- therapy. Nat. Rev. Immunol. 6:295-307.

17. Dieckmann, D.; Plottner, H. (2001) .Ex vivo isolation and characteri- ization of CD4+CD25+ T cells with regulatory properties from human blood. J. Exp. Med. 193:1303-10.

18. Khong, H. T. and Restifo, N. P. (2002).Natural selection of tumour variants in the generation of ,tumour escape phenotypes. Nature Immunol . 3: 999-1005.

19. Curiel, T. J.and et al. (2004).Specific recruitment of regulatory T cells in ovarian carcinoma fosters immune privilege and pre Khong, H. T. and Restifo, N. P. (2002). Natural selection of tumour variants in the generation of ,tumour escape ${ }^{e e}$ phenotypes. Nature Immunol. 3:999-1005.

20. Sakaguchi, S. (2005). Naturally arising Foxp3-expressing CD25+CD4 regulatory $T$ cells in immunological tolerance to self and non-self. Nature Immunol. 6(4): 345-352.

21. Ebert, L.M.; Tan, B.S.; Browning, J.; Svobodova, S.; Russell, S.E.; Kirkpatrick, N.; Gedye, C.; Moss, D.; PingNg, S.; MacGregor, D.; Ian, I. D.; Cebon, J.; and Weisan Chen, W.(2008). The Regulatory T Cell-Associated Transcription Factor FoxP3 Is Expressed by Tumor Cells. Can.Res. 68(8):3001-9.

22. Karanikas, V.; Speletas, M.; Zamanakou, M.; Kalala, F.; Loules, G.; Kerenidi, T.; Barda, A.K.; Gourgoulianis, K.I. and Germenis, A.E. (2008).Foxp3 expression in human cancer cells. J. Transl .Med . 6:19-27.

23. Takenaka, M.; Seki, N.; toh, U.; Hattori, S.; Kawahara, A.; Yamaguchi,T.; Koura, K.; Takahashi, R.; Otsuka, H.; Takahashi,H.; Aiwakuma, N.; Nakagawa, S.; Fujii, T.; Sasada, T.; Yamaguchi, R.; Yano, H.; Shirouzu,K. And Kage,M.(2013). FOXP3 expression in tumor cells and tumor-infiltrating lymphocytes is associated with breast cancer prognosis. Molecular and clinical oncology, 1: 625-632.

24. Zhang, H.Y. and Sun, H. (2010). Up-regulation of FOXP3 inhibits cell proliferation,migration and invasion in epithelial ovarian cancer. Cancer Letter, 287(1): 91-97.

25. Lucas, S.; van Baren, N.; de Smet, C. and Coulie, P. G. (2012). Demethylation of the FOXP3 gene in human melanoma cells precludes the use of this epigenetic mark for quantification of Tregs in unseparated melanoma samples, Int. J. Cancer. 130: 1960-66.

26. Shigematsu, Y; Hanagiri, T.; Shiota, H.; Kuroda, K.; Baba,T.; Ichiki, Y.; Yasuda,M.;Uramoto,H.;Takenoyama,M.;Yasumoto,K.; and Tanaka ,F.(2012). Immunosuppressive effect of regulatory $\mathrm{T}$ lymphocytes in lung cancer, with special reference to their effects on the induction of autologous tumor-specific cytotoxic T lymphocytes. Oncology Letters, 4: 625-630. 
27. Kim, M.; Grimmig, T.; Grimm, M.; Maria Lazariotou,M.; Meier, E.; Andreas Rosenwald, A.; Tsaur, I.; Blaheta, R.; Heemann, U.; Germer, C-T.; Waaga-Gasser, A. M.; and Gasser, M. (2013). Expression of Foxp3 in Colorectal Cancer but Not in Treg Cells Correlates with Disease Progression in Patients with Colorectal Cancer. PLoS ONE 8(1): e53630.

28. Xia, M.; Zhao, M-q.; Wu, K.; Lin,X-y.; Liu,Y. and Ye-jun Qin, Y-j.(2013). Investigations on the clinical significance of FOXP3 protein expression in cervical oesophageal cancer and the number of FOXP3 tumour infiltrating lymphocytes. Journal of International Medical Research , 41(4) :1002-1008.

29. Hu, J-L.; Yang, Z.; Tang, J-R.; Fu,X-Q.; Yao, L-J.(2013).Effects of Gastric Cancer Cells on the Differentiation of Treg Cells. Asian Pac. J. Cancer Prev. 14 (8): 4607-10.

30. Um, S-W.; Lee, S.H.; Kim,H.; Kwon, J.; Kim, H.; Kang, J.S. and Lee, W.J.(2011). The Regulation of FOXP3 Expression by the treatment of TGF- $\beta$ and the Modification of DNA Methylation in Lung Cancer Cell Lines Tuberculosis and Respiratory Diseases, 70(3):206-17.

31. Milne, K.; Ko“ bel, M.; Kalloger, S.E.; Barnes, R.O.; Gao, D. and et al. (2009). Systematic Analysis of Immune Infiltrates in High-Grade Serous Ovarian Cancer Reveals CD20, FoxP3 and TIA-1 as Positive Prognostic Factors .PLoSONE ,4(7): e6412.

32. Finn , O.J. (2008).Molecular Origins of Cancer Cancer Immunology. N. Engl. J .Med. 358:2704-15.

33. Feng, J.; Zhang, X.; Zhu, H.; Wang, X.; Ni, S.and Huang, J. (2012).High Expression of FoxP1 Is Associated With Improved Survival in Patients With Non-Small Cell Lung Cancer. Am. J. Clin. Pathol. 138:230-235.

34. Dimitrakopoulos, F-I.d.; papadaki, h.; Antonacopoulou, A.G.; Kottorou, A.; Gotsis, A.D.; Scopa, C.; Kalofonos, H.P.; and Mouzaki, A.(2011). Association of FOXP3 Expression with Non-small Cell Lung Cancer. Anticancer Research, 31 (5): 1677-1683.

35. Salama ,P.;Phillips , M.; Grieu, F.; Morris, M.; Zeps, N. and et al. (2008) Tumor-Infiltrating FOXP3+ T Regulatory Cells Show Strong Prognostic Significance in Colorectal Cancer. J. Clin. Oncol. 27: 186-192

36. Zuo, T.; Liu, R.; Zhang, H.; Chang, X.; Liu, Y.; Wang, L.; heng, P. and Liu, Y.(2007a.). FOXP3 is a novel transcriptional repressor for the breast cancer oncogene SKP2. J. Clin. Invest . 117(12):3765-73.

37. Tao, H.; Mimura, Y.; Aoe, K.; Kobayashi, S.; Yamamoto, H.; Matsuda, E.; Okabe, K.; Matsumoto, T.; Sugi, K. and Ueoka, H. (2012). Prognostic potential of FOXP3 expression in non-small cell lung cancer cells combined with tumor-infiltrating regulatory T cells. Lung Cancer, 75(1): 95-101.

38. Kinoshita, T.; Ishii, G.; Hiraoka, N.; Hirayama,S.; Yamauchi, C. et al. (2013).Forkhead box P3 regulatory T cells coexisting with cancer associated fibroblasts are correlated with apoor outcome in lung adenocarcinoma .Cancer Sci . 104( 4 ): 409-415. 